\title{
Remodeling of Membrane Properties and Dendritic Architecture Accompanies the Postembryonic Conversion of a Slow into a Fast Motoneuron
}

\author{
Carsten Duch and R. B. Levine \\ Division of Neurobiology, University of Arizona, Tucson, Arizona 85721
}

\begin{abstract}
The postembryonic acquisition of behavior requires alterations in neuronal circuitry, which ultimately must be understood as specific changes in neuronal structure, membrane properties, and synaptic connectivity. This study addresses this goal by describing the postembryonic remodeling of the excitability and dendritic morphology of an identified motoneuron, MN5, which during the metamorphosis of Manduca sexta (L.) changes from a slow motoneuron that is involved in larval-crawling behavior into a fast adult flight motoneuron. A fivefold lower input resistance, a higher firing threshold, and an increase in voltage-activated $\mathrm{K}^{+}$ current contribute to a lower excitability of the adult MN5, which is a prerequisite for its newly acquired behavioral role. In addition, the adult MN5 displays larger $\mathrm{Ca}^{2+}$ currents. The dendrites of MN5 undergo extensive remodeling. Drastic regression of larval dendrites during early pupal stages is followed by rapid growth of
\end{abstract}

new dendrites. Critical changes in excitability take place during the onset of adult dendrite formation. Larval $\mathrm{Ca}^{2+}$ currents are absent when dendritic remodeling is most dramatic but increase markedly during later development. Changes in $\mathrm{Ca}^{2+}$ and $\mathrm{K}^{+}$ currents follow different time courses, allowing the transient occurrence of $\mathrm{Ca}^{2+}$ spikes during pupal stages when new dendritic branching ceases. The adult MN5 can produce prolonged $\mathrm{Ca}^{2+}$ spikes after $\mathrm{K}^{+}$currents are reduced. We suggest that alterations in $\mathrm{Ca}^{2+}$ and $\mathrm{K}^{+}$currents are necessary for the participation of MN5 in flight behavior and that the transient production of $\mathrm{Ca}^{2+}$ spikes may influence postembryonic dendritic remodeling.

Key words: postembryonic development; calcium current; potassium current; neuronal differentiation; insect; Manduca sexta; CNS; flight behavior
Changes in the excitability and dendritic architecture of central neurons accompany the development and plasticity of behavior (McCobb et al., 1989, 1990; Baines and Bate, 1998; Gao and Ziskind-Conhaim, 1998; Reynolds et al., 1998; Sun and Dale, 1998; Martin-Caraballo and Greer, 1999). As neuronal structure, biophysical properties, and synaptic interactions differentiate or are modified postembryonically, the activity patterns of the mature CNS emerge (Casanovas and Meyrand, 1995). These emergent activity patterns, in turn, influence neuronal differentiation (Spitzer, 1991; Ribiera and Spitzer, 1992; Muller et al., 1998). Activity-dependent $\mathrm{Ca}^{2+}$ influx controls neuronal growth (Cohan et al., 1987; Mattson et al., 1988; Fields et al., 1990; Haydon and Zoran, 1994), and transient patterns of electrical activity regulate synaptic input (Shatz, 1990). A satisfactory understanding of these interdependent processes requires a detailed description of the temporal relationship between the structural and functional remodeling of identified neurons in a behavioral context.

Although behavior changes postembryonically in all organisms, the particularly extreme example of metamorphosis offers a unique model system for such studies. In holometabolous insects the participation of central neurons in larval behavior ceases as novel behavior is acquired during postembryonic life (Weeks and Levine, 1990). For example, in Manduca sexta (L.), five motoneurons that innervate slowly contracting muscles of the larval dorsal body wall persist throughout metamorphosis to innervate the new, fastcontracting, dorsal longitudinal flight muscle (DLM) of the adult (Casaday and Camhi, 1976; Rheuben and Kammer, 1980; Duch et al., 2000). Identified flight motoneurons, such as MN5, mediate slow tonic contractions of larval target muscles during crawling but

\footnotetext{
Received April 19, 2000; accepted June 28, 2000.

We gratefully acknowledge the support by National Institutes of Health Grant NS 28495 and by the Deutsche Forschungsgemeinschaft Fellowship DU 331/2-1 (C.D.). We thank Dr. C. Consoulas for many helpful comments on this manuscript.

Correspondence should be addressed to Dr. Carsten Duch, University of Arizona, Division of Neurobiology, 611 Gould-Simpson Building, Tucson, AZ 85721. E-mail: duch@neurobio.arizona.edu.

Copyright (C) 2000 Society for Neuroscience $0270-6474 / 00 / 206950-12 \$ 15.00 / 0$
}

fast twitch contractions of newly generated adult target muscles during flight.

Many motoneurons that survive metamorphosis to participate in adult-specific behavior undergo dendritic remodeling (Levine and Truman, 1982, 1985; Truman and Reiss, 1988; Weeks and ErnstUtzschneider, 1989; Kent and Levine, 1993). Little is known, however, about electrophysiological changes that may accompany structural remodeling and the development of new behavior. The isolated somata of cultured Manduca leg motoneurons display differences in ionic currents among different developmental stages (Hayashi and Levine, 1992), some of which are mediated by the steroid hormone 20-hydroxyecdysone (Grünewald and Levine, 1998). The functional consequences of such changes have yet to be determined, however, and it is not clear how accurately the characteristics of isolated motoneuron cell bodies reflect the properties of cells undergoing the normal remodeling of dendrites and synaptic interactions in vivo.

This study describes both the dendritic remodeling of MN5 and changes in its membrane properties that are appropriate for the postembryonic conversion of a slow into a fast motoneuron. Moreover, specific changes in excitability and voltage-dependent ionic currents are correlated temporally with critical phases of dendritic remodeling.

\section{MATERIALS AND METHODS}

Animals. Manduca sexta obtained from a laboratory culture were reared on an artificial diet (Bell and Joachim, 1976) under a long-day photoperiod regimen ( $17: 7 \mathrm{hr}$ light/dark cycle) at $26^{\circ} \mathrm{C}$ and $\sim 60 \%$ humidity. Both chronological and morphological criteria were used for the staging of animals (Nijhout and Williams, 1974; Bell and Joachim, 1976; Tolbert et al., 1983; Consoulas et al., 1996). In summary, L5 represents the fifth larval instar, W0 signifies the first day of wandering, and W1 to W4 represent the remaining $4 \mathrm{~d}$ of wandering. $\mathrm{P} 0$ indicates the day of the pupal molt, and P1 to $\mathrm{P} 18$ are the following $18 \mathrm{~d}$ of adult development.

Dissection for intracellular recordings. The animals were anesthetized by chilling on ice for $15 \mathrm{~min}$. Animals were dissected along the dorsal midline and superfused with saline. The thoracic and the first two abdominal ganglia were removed, transferred into a Sylgard-coated Petri dish, and pinned down at the cut ends of their lateral nerves in saline. The ganglionic sheath was removed mechanically with a fine pair of forceps. Nerve 1 of the 


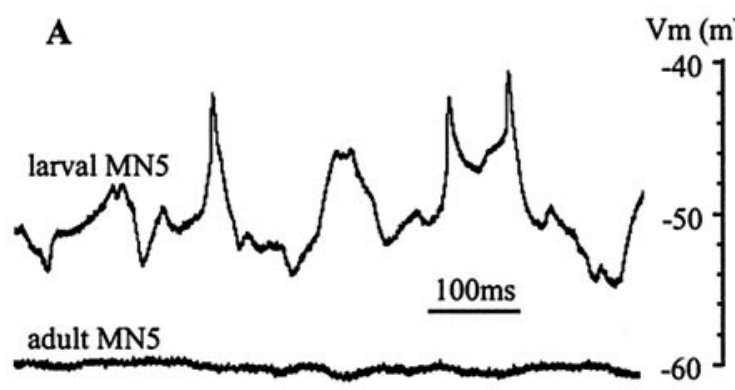

B
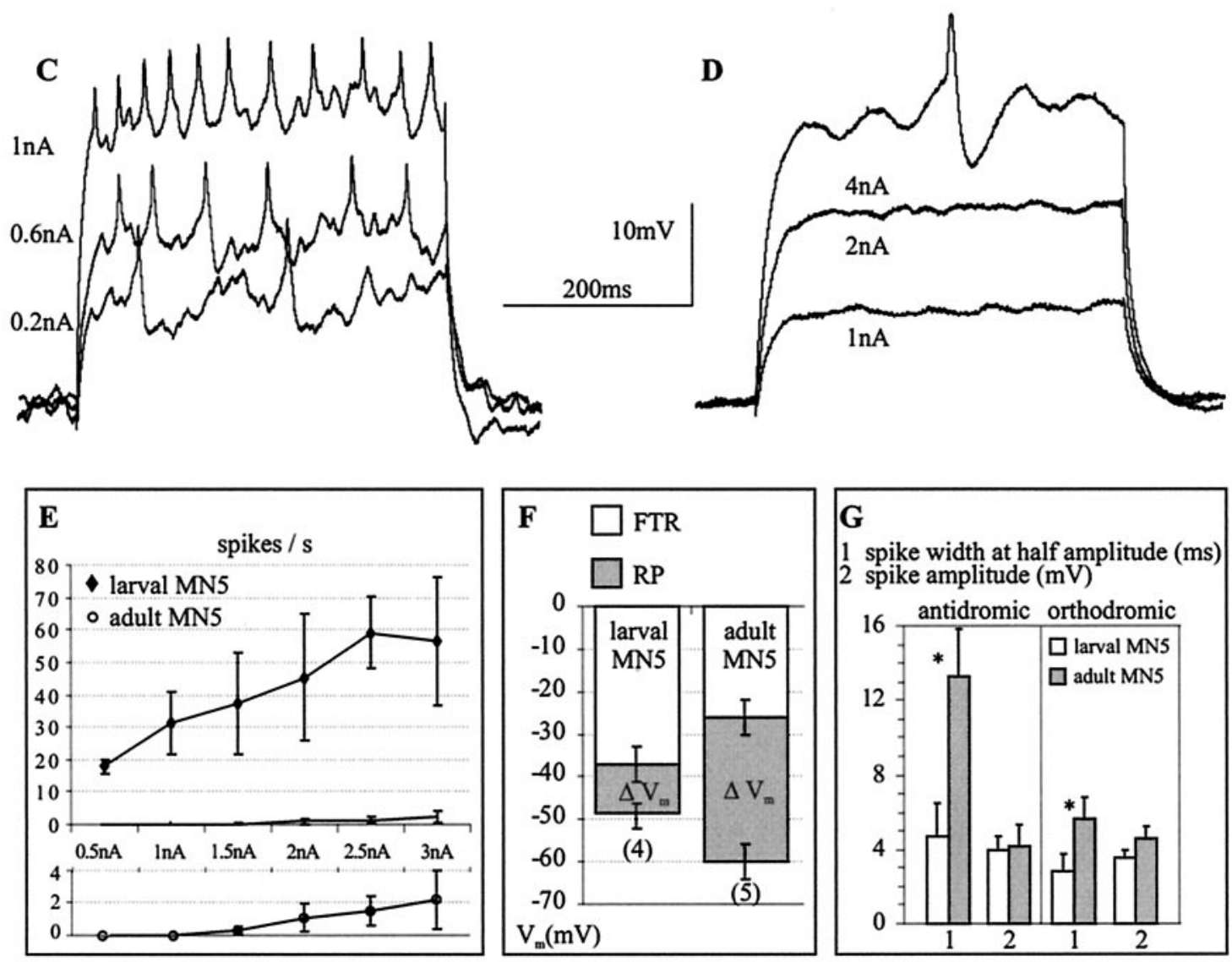

Figure 1. Excitability of the "slow" larval and the "fast" adult MN5. A, Representative intracellular recordings of spontaneous activity recorded from the cell body in the larval (top trace) and the adult (bottom trace) MN5 in the isolated ganglion preparation. B, Larval (dotted lines) and adult (solid lines) orthodromically and antidromically evoked spikes. Each trace represents a signal average of eight spikes taken from a representative recording. $C$, $D$, Representative responses of the larval $(C)$ and the adult $(D) \mathrm{MN} 5$ to current injection into the soma. $E$, Injected current plotted against evoked firing frequency (I/F relationship). Top, I/F relationships for the larval and the adult MN5 created from five recordings each. Bottom, The adult I/F relationship shown again at an expanded scale. $F$, Average resting potential and average firing threshold for the larval and the adult MN5. Error bars represent SDs. The average voltage difference between the resting potential $(R P)$ and the firing threshold $(F T R)$ is defined as $\Delta V_{m}$ and indicated by gray bars. $G$, Average spike amplitude (millivolts) and average spike duration at half amplitude (milliseconds) for the antidromically and for the orthodromically evoked spike of the larval (white bars) and the adult (gray bars) MN5. Statistically significant differences between the larval and the adult stages are indicated by asterisks $(p<0.001)$. Error bars represent SDs.

mesothoracic ganglion was left intact toward its specific peripheral branch that contains only the axons of the five DLM motoneurons (Duch et al., $2000)$. MN5 is the only motoneuron in the mesothoracic ganglion that carries an axon in this particular nerve branch (Duch et al., 2000). Antidromic stimulation from this nerve branch was used to identify MN5 during intracellular recordings.

Intracellular staining techniques. Rhodamine Dextran 3000 (Molecular Probes, Eugene, OR) was used for all intracellular stainings. The tips of thin-walled borosilicate electrodes (resistances, 20-25 M $\Omega$ ) were filled with $5 \%$ dextran in $1 \mathrm{M}$ potassium acetate. The electrode shafts were filled with $1 \mathrm{~m}$ potassium acetate, and an air bubble was left between the tip and the shaft to prevent dye dilution. After intracellular penetration and antidromic identification of MN5, dye was injected iontophoretically by applying depolarizing current pulses of 3-4 nA amplitude and $200 \mathrm{msec}$ duration with a frequency of $2.5 \mathrm{~Hz}$ for 30-60 min. After dye injection, ganglia were left in saline for an additional $30 \mathrm{~min}$ to allow dye diff usion. Subsequently, ganglia were fixed in $4 \%$ paraformaldehyde and washed three times in $10 \mathrm{~mm}$ PBS, $\mathrm{pH} 7.4$, for $15 \mathrm{~min}$ each. Then preparations were dehydrated in ethanol, cleared in methyl salicylate, and mounted in Permount (Fisher Scientific, Fair Lawn, NJ).

Confocal microscopy. Digital images were captured on a Nikon PCM 2000 laser-scanning confocal microscope using Simple PCI (Compix, Tualatin, OR) image acquisition software. Images were further processed using Corel Draw 8 software (Corel, Ottawa, Ontario, Canada). Preparations were scanned with a helium-neon laser line with an excitation maximum at $546 \mathrm{~nm}$ using a long-pass filter at $565 \mathrm{~nm}$. All preparations were scanned with a $40 \times$ lens at optical planes of $1 \mu \mathrm{m}$. All images shown are the projections of all optical planes of a given stack into one focal plane, to show the entire dendritic field in one two-dimensional image.

Electrophysiology. An Axoclamp 2B amplifier (Axon Instruments, Foster City, CA) was used for all recordings. Synaptic potentials and spike shapes were recorded in bridge mode with the same electrode shapes used for intracellular dye injections (see above), but electrode tips were coated with silicon oil. Input resistance was determined in discontinuous current-clamp mode (DCC) to avoid the problem of an inadequate bridge balance, which can occur because of changes in electrode resistance while penetrating the 

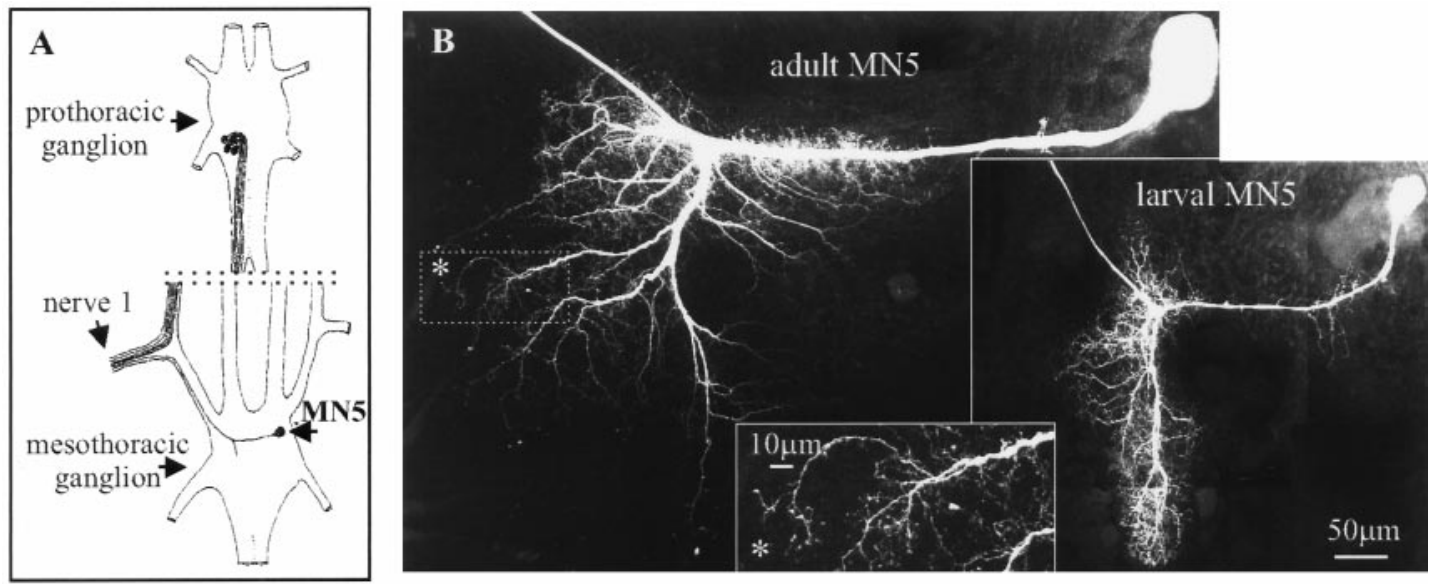

Figure 2. A, Schematic drawing of the arrangement of the five motoneurons that innervate the mesothoracic DLM. MN5 is the only DLM motoneuron that is located in the mesothoracic ganglion and that can, therefore, be individually identified by antidromic stimulation throughout all developmental stages. B, Confocal images of the adult and the larval MN5. Inset, High-order branches of the adult MN5 depicted in a selective enlargement (region enclosed in the dotted line in the adult image; see asterisk).
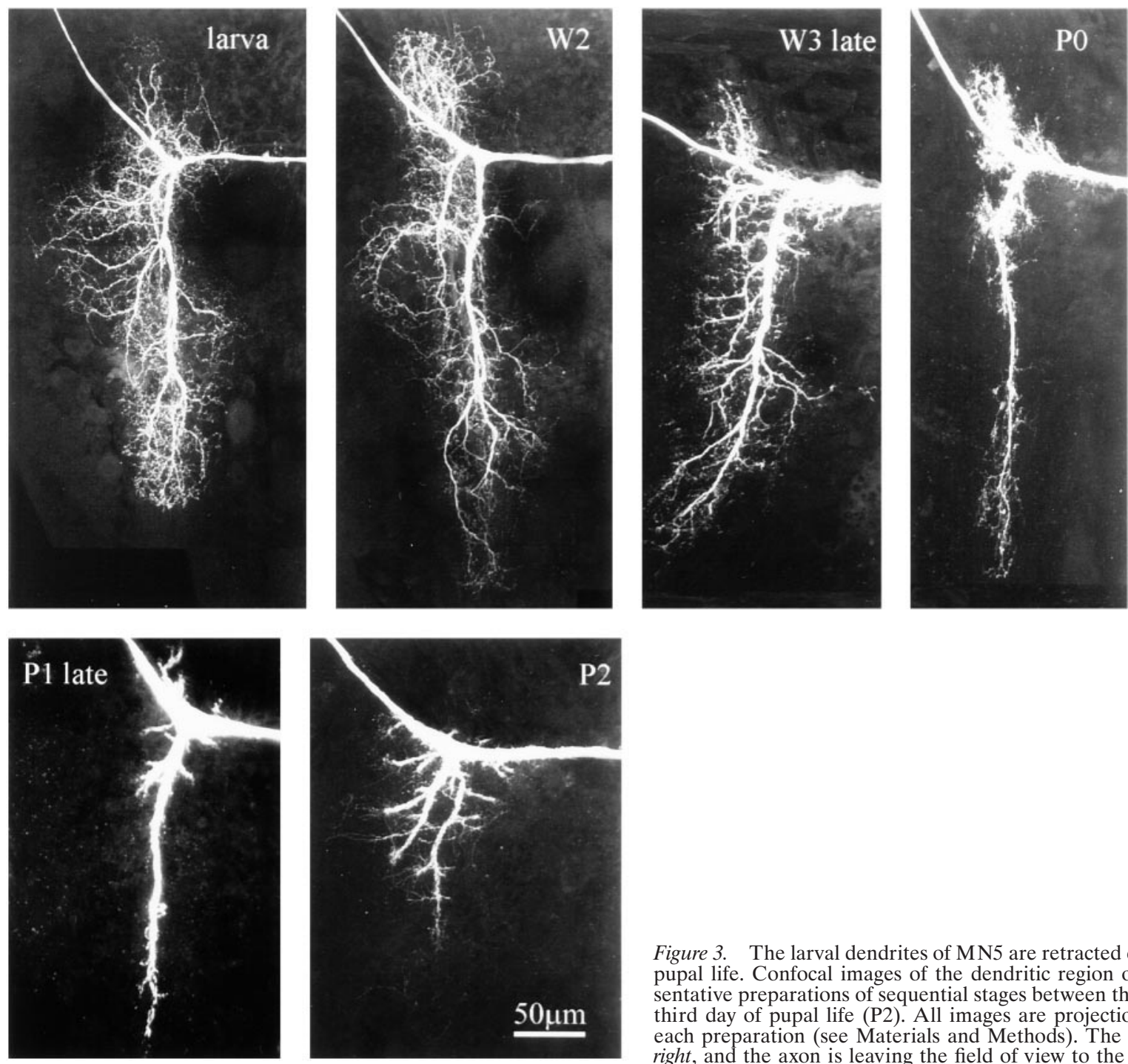

Figure 3. The larval dendrites of MN5 are retracted during late larval and early pupal life. Confocal images of the dendritic region of MN5 taken from representative preparations of sequential stages between the fifth larval instar and the third day of pupal life (P2). All images are projections of all optical planes of each preparation (see Materials and Methods). The cell body is located to the right, and the axon is leaving the field of view to the left. 

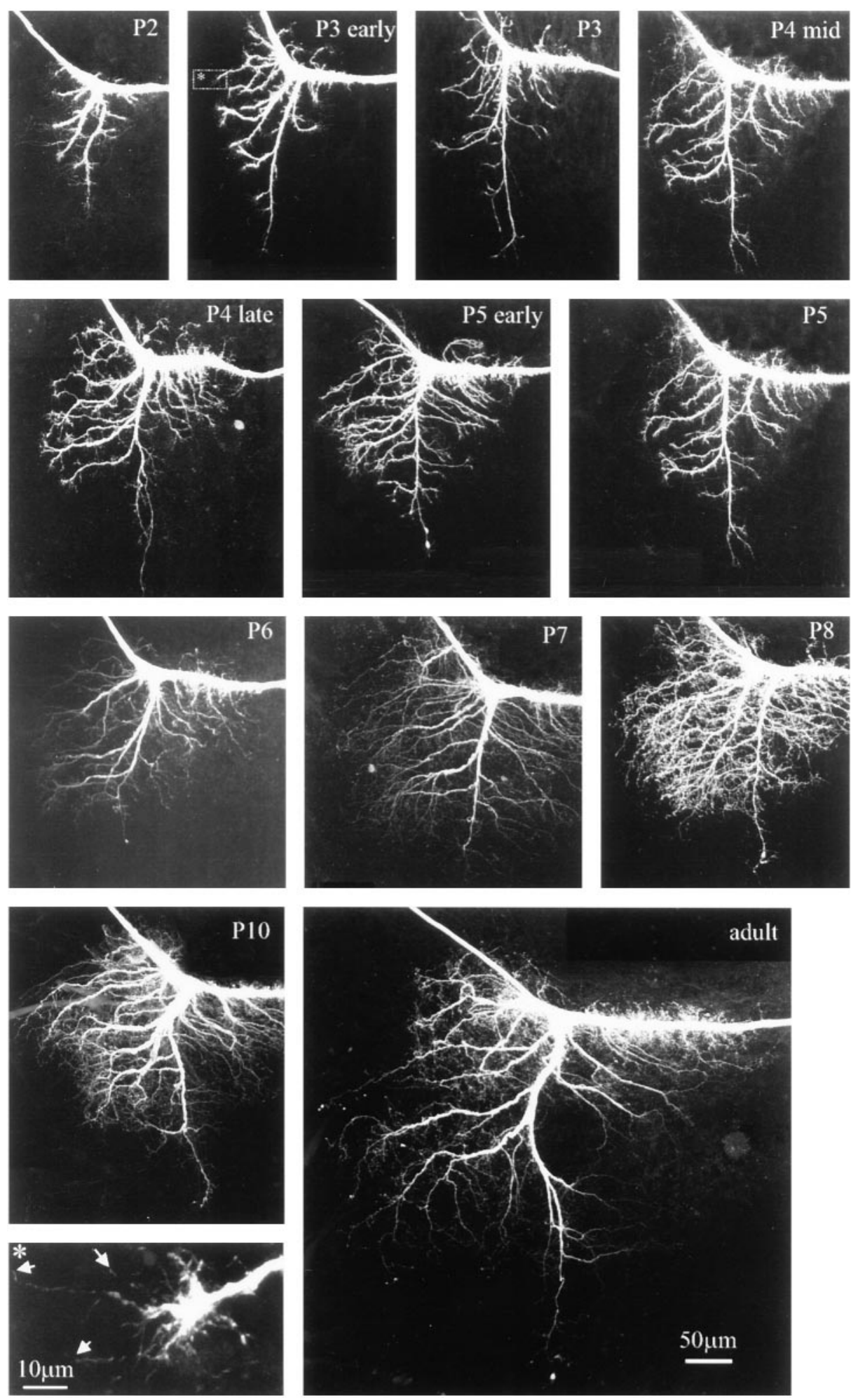

Figure 4. Sprouting and subsequent growth of new adult dendrites during pupal life. Confocal images of the dendritic region of MN5 taken from representative preparations of sequential stages between the third day of pupal life (P2) and adulthood. All images are projections of all optical planes of each preparation (see Materials and Methods). Inset (bottom left), The region enclosed in the dotted line in the stage P3 early preparation. Note the growth cone-like structure at the tip of the growing dendrite. Filopodia-like processes are marked by arrows.

ganglionic tissue. Electrodes with resistances between 20 and $25 \mathrm{M} \Omega$ were filled either with $1 \mathrm{M}$ potassium acetate or with $5 \%$ rhodamine dextran in $1 \mathrm{M}$ potassium acetate. No differences between these methods were observed. Sampling rates between 3.5 and $5 \mathrm{kHz}$ were reached without any signal cutoff. The slope input resistance was calculated from the linear portion of the voltage/current relationship using $0.2 \mathrm{nA}$ current steps between -2 and $+0.2 \mathrm{nA}$. The firing threshold was measured as the minimum depolarization from the resting potential necessary to trigger an action potential.

Voltage-activated $\mathrm{Ca}^{2+}$ and $\mathrm{K}^{+}$currents were measured in discontinuous single-electrode voltage-clamp mode (dSEVC). Electrodes of 12-15 $\mathrm{M} \Omega$ resistance were filled with $2 \mathrm{M}$ potassium acetate (for measuring $\mathrm{K}^{+}$current) or with $1.5 \mathrm{M}$ cesium chloride (for measuring $\mathrm{Ca}^{2+}$ currents). In dSEVC mode, sampling rates of $3.5-5 \mathrm{kHz}$ could be used without any signal cutoff. The amplifier was controlled using pClamp8 software (Axon Instruments) running on an IBM-compatible personal computer. A linearly scaled leak current obtained from hyperpolarizing steps from -60 to $-90 \mathrm{mV}$ was subtracted from each current trace before further analysis with Clampfit8 (Axon Instruments). All traces shown are averages of at least four trials. All recordings were made at room temperature $\left(22-25^{\circ} \mathrm{C}\right)$

Solutions. External saline for dissection and recording consisted of (in $\mathrm{mM}$ ): $140 \mathrm{NaCl}, 5 \mathrm{KCl}, 4 \mathrm{CaCl}_{2}, 28 \mathrm{D}$-glucose, and $5 \mathrm{HEPES}$; $\mathrm{pH}$ was adjusted to 7.4 with $1 \mathrm{M} \mathrm{NaOH}$. $\mathrm{K}^{+}$conductance saline contained (in $\mathrm{mm}$ ): $140 \mathrm{NaCl}, 5 \mathrm{KCl}, 4 \mathrm{MgCl}_{2}, 28 \mathrm{D}$-glucose, $5 \mathrm{HEPES}$, and $0.5 \mathrm{CdCl}_{2} \cdot \mathrm{Ca}^{2+}$ conductance saline contained (in mM): $110 \mathrm{NaCl}, 5 \mathrm{KCl}, 4 \mathrm{MgCl}_{2}, 28$ D-glucose, 5 HEPES, and 30 tetraethylammonium chloride (TEA; Sigma, St. Louis, MO). After antidromic identification of MN5, a small volume of 
A
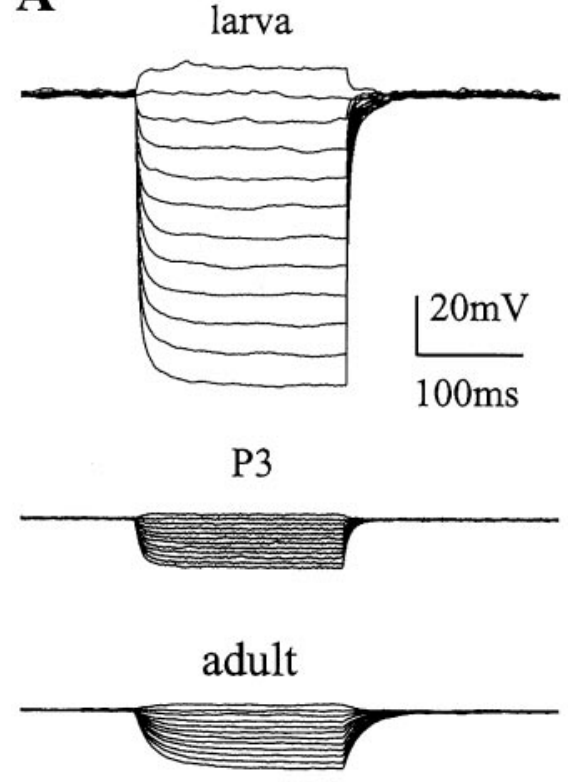

C

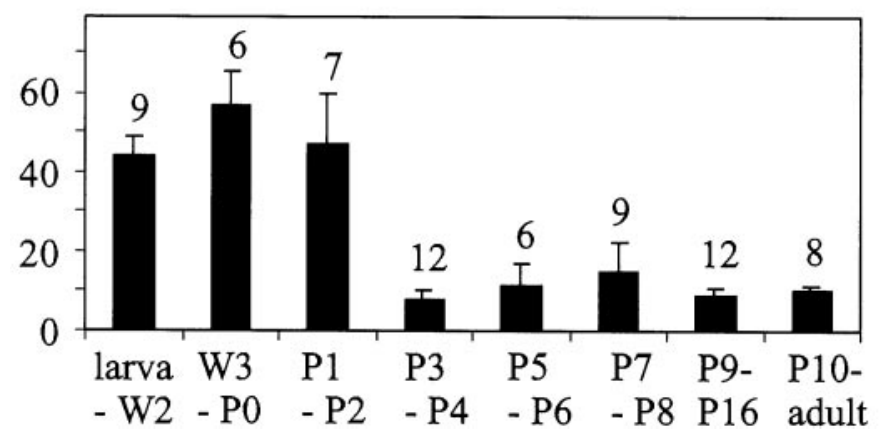

Figure 5. Changes in input resistance during postembryonic development. The input resistance of MN5 was recorded in DCC mode at different developmental stages. $A$, Representative voltage responses of MN5 at the larval stage, pupal stage P3, and the adult stage to 12 steps of current injection between -2 and $0.2 \mathrm{nA}$. $B$, Confocal images of the cell bodies of MN5 at different developmental stages. $C$, Average input resistances for different developmental stages. The number of recordings for each group is presented above each bar. Error bars represent SDs.

concentrated tetrodotoxin (TTX; $10^{-2} \mathrm{M}$ in $\mathrm{H}_{2} \mathrm{O}$; Sigma) was added to achieve a final concentration of $10^{-8} \mathrm{M}$ in the bath.

\section{RESULTS}

\section{Differences in excitability between the larval and the adult MN5}

The excitability of MN5 changed during postembryonic life. In the isolated ganglion preparation, the larval MN5 received many synaptic inputs and fired spontaneously $(n=8)$, whereas the adult MN5 received fewer synaptic inputs, and no spontaneous action potentials were observed in any of 12 preparations (Fig. $1 A$ ). In addition the resting membrane potential of the adult MN5 was more hyperpolarized than was that of the larval MN5 (Fig. 1 $A, F$ ). The larval MN5 displayed tonic firing in response to current injection into the soma (Fig. $1 C$ ). In contrast, the adult MN5 required current injection of higher amplitudes and responded only occasionally with a single spike (Fig. 1D). The larval MN5 had a linear current/firing frequency relationship between 0.5 and $2.5 \mathrm{nA}$ current injection, before reaching a maximal firing frequency of $\sim 60 \mathrm{~Hz}$ (Fig. $1 E$ ). In contrast, in the adult MN5 only two spikes per second occurred on average at $3 \mathrm{nA}$ of current injection (Fig. $1 E)$. The lower excitability of the adult MN5 was caused in part by its lower resting membrane potential and its higher firing threshold. The membrane voltage difference between the resting potential and firing threshold was $33 \mathrm{mV}$ for the adult but only $11 \mathrm{mV}$ for the larval MN5 (Fig. 1F).

Spike shape differed significantly between the larval and the adult stage (Fig. $1 B, G$ ). Antidromically evoked spikes displayed a threefold longer duration at half amplitude in the adult. Spikes evoked by current injection into the soma had a twofold longer duration in the adult. Spike amplitude did not differ significantly between stages. Neither the orthodromic nor the antidromic spikes were $\mathrm{Ca}^{2+}$ dependent, because replacing $\mathrm{Ca}^{2+}$ with $\mathrm{Mg}^{2+}$ had no effect on spike shape in either developmental stage. TTX blocked the spikes at both stages.

\section{Remodeling of the dendrites of MN5}

The adult MN5 was significantly larger than the larval MN5 (Fig. $2 B$ ). In both stages the cell body was located on the contralateral side of the mesothoracic ganglion in relation to the target muscle. The elaborate dendritic field was located ipsilateral to the target muscle. All compartments, including dendrites, axon, and cell body, of the adult MN5 were larger than those of the larval MN5 [quantitative morphometric analysis (F. Libersat and C. Duch, unpublished results)]. This was correlated with an increase in ganglionic size between the larval and the adult stage. To understand whether the changes in the excitability of MN5 were caused by the increase in cell size during metamorphosis or by changes in membrane properties, we studied the active and passive membrane properties and the morphology of MN5 throughout postembryonic development.

Although the larval and the adult MN5 exhibited similarities in their central projections, the dendritic field underwent drastic remodeling during metamorphosis. The end of larval life was accompanied by a regression of most larval dendrites (Fig. 3). No changes in the dendritic architecture were observed until stage W2 (Fig. 3). Dendritic regression started on the third day of the wandering phase (Fig. 3, W3). All secondary and higher order dendrites became thicker and more compact as compared with earlier larval stages (Fig. 3, larva, W2). Two days later in development, on the first day of pupal life (Fig. 3, P0), most secondary and higher order larval dendrites were lost, although the length of the primary dendrite remained relatively constant. During the following $2 \mathrm{~d}$ of pupal life (Fig. 3, P1, P2) dendritic regression continued, and the primary dendrite became shorter. The third day of pupal life (Fig. 3, P2) was the stage of maximal dendritic regression. The following $6 \mathrm{~d}$ of pupal life were accompanied by dramatic dendritic branching and growth (Fig. 4). At early stage P3 the dendrites formed growth cone-like structures at their tips and began to grow. These growth cone-like structures (see Fig. 4, inset) were observed between pupal stages P3 and P5 (Fig. 4), although dendritic growth and the sprouting of higher order dendrites continued at least until pupal stage P8 (Fig. 4). Dendritic branching ceased between pupal stages P8 and P10 (Fig. 4). Therefore, most adult dendrites were formed by $40-50 \%$ of pupal life, although the dendrites, the neurite, and the cell body grew in overall size until pupal stage P16.

\section{Changes in electrical properties of MN5}

The adult MN5 had a fourfold to fivefold lower input resistance as compared with the larval MN5 (Fig. $5 A$ ), perhaps contributing to its lower excitability (Fig. $1 C-E$ ). To test whether this was simply a consequence of the larger size of the adult motoneuron, the input resistance of MN5 was followed throughout development. Input resistance did not decrease gradually while MN5 was growing but instead decreased dramatically between pupal stages P2 and P3 (Fig. 5C), although the cell body size increased gradually throughout all stages of metamorphosis (Fig. $5 B$ ) and the dendrites grew between pupal stages P2 and P16 (Fig. 4). Therefore, the abrupt decrease in input resistance within $1 \mathrm{~d}$ of pupal life was not caused 

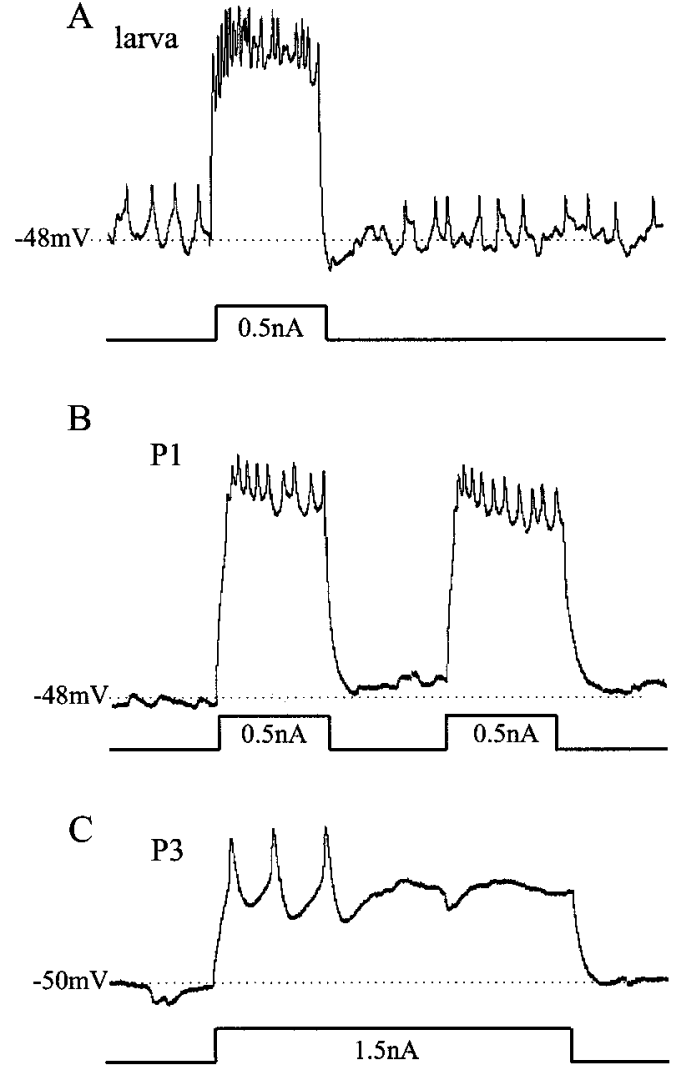
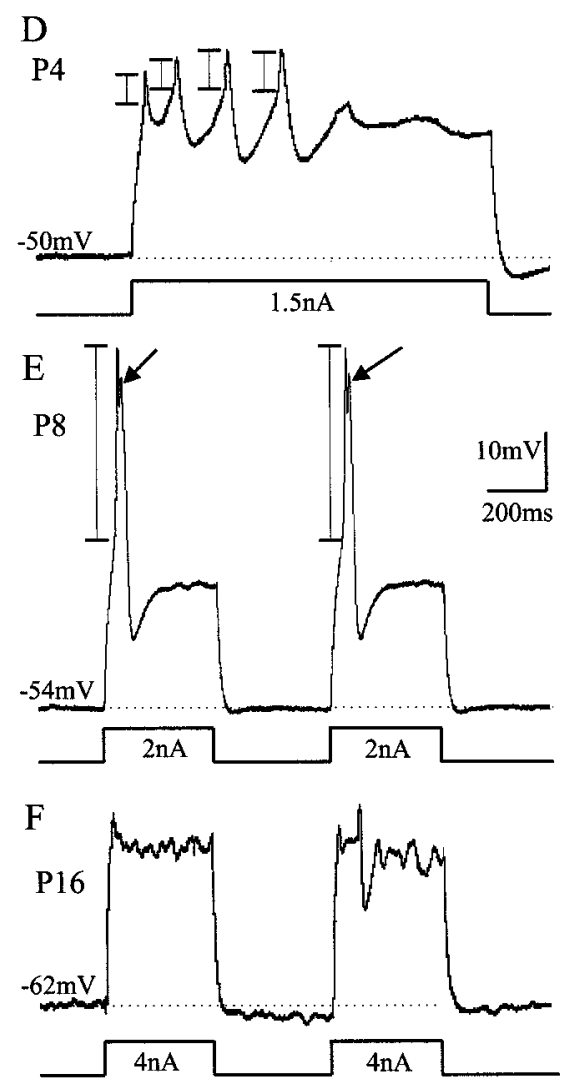

Figure 6. Developmental changes in firing responses of MN5. Representative intracellular recordings of firing responses of MN5 to somatic current injections at different developmental stages $(A$, larval stage; $B, \mathrm{P} 1 ; C, \mathrm{P} 3$; $D, \mathrm{P} 4 ; E, \mathrm{P} 8 ; F, \mathrm{P} 16)$. In all preparations, MN5 was stimulated by square-pulse current injections into the soma at $\sim 0.5$ $\mathrm{nA}$ above the firing threshold, as indicated below each voltage trace. The horizontal dotted lines indicate the resting membrane potentials. The vertical bars in $D$ and $E$ indicate where the action potential amplitude was measured. At pupal stage P3 $(C)$, action potential amplitude and width increase, and MN5 responds phasically rather than tonically as compared with earlier stages $(A, B)$. A longer current pulse was injected in $C$ and $D$ to illustrate this fact. At pupal stage P8 $(E)$, large-amplitude action potentials were evoked (arrows). At pupal stage $16(F)$, MN5 fired only occasionally after current injections into the soma. simply by a sudden increase in cell size. By comparison, variations of input resistance that occurred during other developmental stages were minor (Fig. $5 C$ ).

The active properties of MN5 were also modified during postembryonic life. Spike shape differed not only between the larval and the adult stage (Fig. 1) but changed more drastically during specific pupal stages (Fig. 6). Before pupal stage P2, the spike shape, the tonic firing response of MN5, and the spontaneous patterns of postsynaptic potentials (PSPs) remained larval-like (Fig. $6 A, B$ ). In fact, MN5 received many PSPs at all stages of dendritic regression (Fig. 6B, P1). At pupal stage P3, which also marked the onset of dendritic growth, both the amplitude and duration of the spikes increased (Fig. 6C). Furthermore, MN5 responded phasically rather than tonically to current injection (Fig. $6 C, D$ ). This change in responsiveness to current injection was correlated in time with the large decrease in input resistance (Fig. 5).

A dramatic change in spike shape occurred during pupal stages P7 to P9, when dendritic sprouting ceased. At pupal stage P8, action potential amplitude was eightfold larger than that at pupal stage P4, measured as the distance from firing threshold to peak (see Fig. 6D,E, vertical bars). This prominent action potential, which was always followed by an afterhyperpolarization, occurred only during pupal stages P7 to P9 and was not affected by bath application of TTX. In contrast, at all other stages the action potentials could be blocked by bath application of TTX $\left(10^{-8} \mathrm{M}\right)$. In 3 out of 12 recordings of MN5 at pupal stages P7, P8, and P9, fast events were clearly visible on top of the prominent TTXindependent action potential (see Fig. 6E, arrows). These fast events could be blocked by bath application of TTX. From pupal stage P10 onward, the action potential was of the adult shape and amplitude (Fig. $6 F$ ). Furthermore, the low excitability of the adult MN5 (Fig. 1) was established by pupal stages P10 to P11.

Unlike the small $\mathrm{Na}^{+}$-dependent action potentials that ordinarily invade the somata of insect motoneurons passively, the prominent TTX-independent action potentials that occurred between pupal stages P7 and P9 were dependent on external $\mathrm{Ca}^{2+}$ (Fig. 7). Replacing $\mathrm{Ca}^{2+}$ with $\mathrm{Mg}^{2+}$ in the bath led to a reduction in spike amplitude (Fig. $7 A$ ). Figure $7 B$ shows selective time points of the continuous recording shown in Figure $7 A$. In regular saline, four large-amplitude action potentials were evoked by somatic current injection. Thirty seconds after $\mathrm{Ca}^{2+}$ was replaced with $\mathrm{Mg}^{2+}$ only the first two of the four spikes were of full amplitude, and by $90 \mathrm{sec}$ none of the four spikes was of full amplitude (Fig. $7 B$ ). The small action potentials that remained could be blocked fully by bath application of TTX $\left(10^{-8} \mathrm{M}\right.$; data not shown). Replacing $\mathrm{Mg}^{2+}$ with $\mathrm{Ca}^{2+}$ in the bath led to a full recovery of the action potential amplitude (Fig. 7A,B). Addition of the nonspecific $\mathrm{Ca}^{2+}$ current blocker $\mathrm{Cd}^{2+}[0.5 \mathrm{~mm}$ (Hayashi and Levine, 1992)] to the bath solution reduced the spike amplitude irreversibly (Fig. $7 C$ ). Between pupal stage 10 and the adult, the action potentials were not dependent on external $\mathrm{Ca}^{2+}$, and $\mathrm{Cd}^{2+}$ did not affect their shape, but they could be blocked by TTX. Therefore, we use the term " $\mathrm{Ca}^{2+}$ spike" for the $\mathrm{Ca}^{2+}$-dependent action potential that occurs only at the pupal stages P7, P8, and P9, and the term "Na ${ }^{+}$spike" for the TTX-sensitive action potentials.

The transient $\mathrm{Ca}^{2+}$ spike could not only be evoked by current injection into the soma of MN5 but also occurred spontaneously and could be elicited by stimulation of sensory nerves (Fig. 7D). Between pupal stages P7 and P9, the action potential threshold was $-41 \pm 4 \mathrm{mV}(n=8)$, and the average resting potential was $54 \pm$ $3 \mathrm{mV}(n=12)$.

The size of the $\mathrm{Ca}^{2+}$ spike increased continually from late pupal stage P6 to pupal stage P8 (Fig. $8 A$ ). Replacing $\mathrm{Ca}^{2+}$ with $\mathrm{Mg}^{2+}$ in the bath did not affect the spike shape at early pupal stage P6 (Fig. 8A). Approximately $12 \mathrm{hr}$ later in development $\sim 30 \%$ of the action potential amplitude was $\mathrm{Ca}^{2+}$ dependent (Fig. 8A). At pupal stage $\mathrm{P} 7,60 \%$ and, at pupal stage $\mathrm{P} 8,80 \%$ of the spike amplitude was $\mathrm{Ca}^{2+}$ dependent. The $\mathrm{Ca}^{2+}$ component was absent in the small action potentials recorded from MN5 later than pupal stage P10. However, in these later pupal stages and in the adult, it could be unmasked by bath application of TEA (Fig. $8 B$ ). This suggests that an increase in $\mathrm{K}^{+}$current at approximately pupal stage 10 ordinarily masked the $\mathrm{Ca}^{2+}$ spike. In vivo voltage-clamp experiments were performed to reveal the ionic currents underly- 

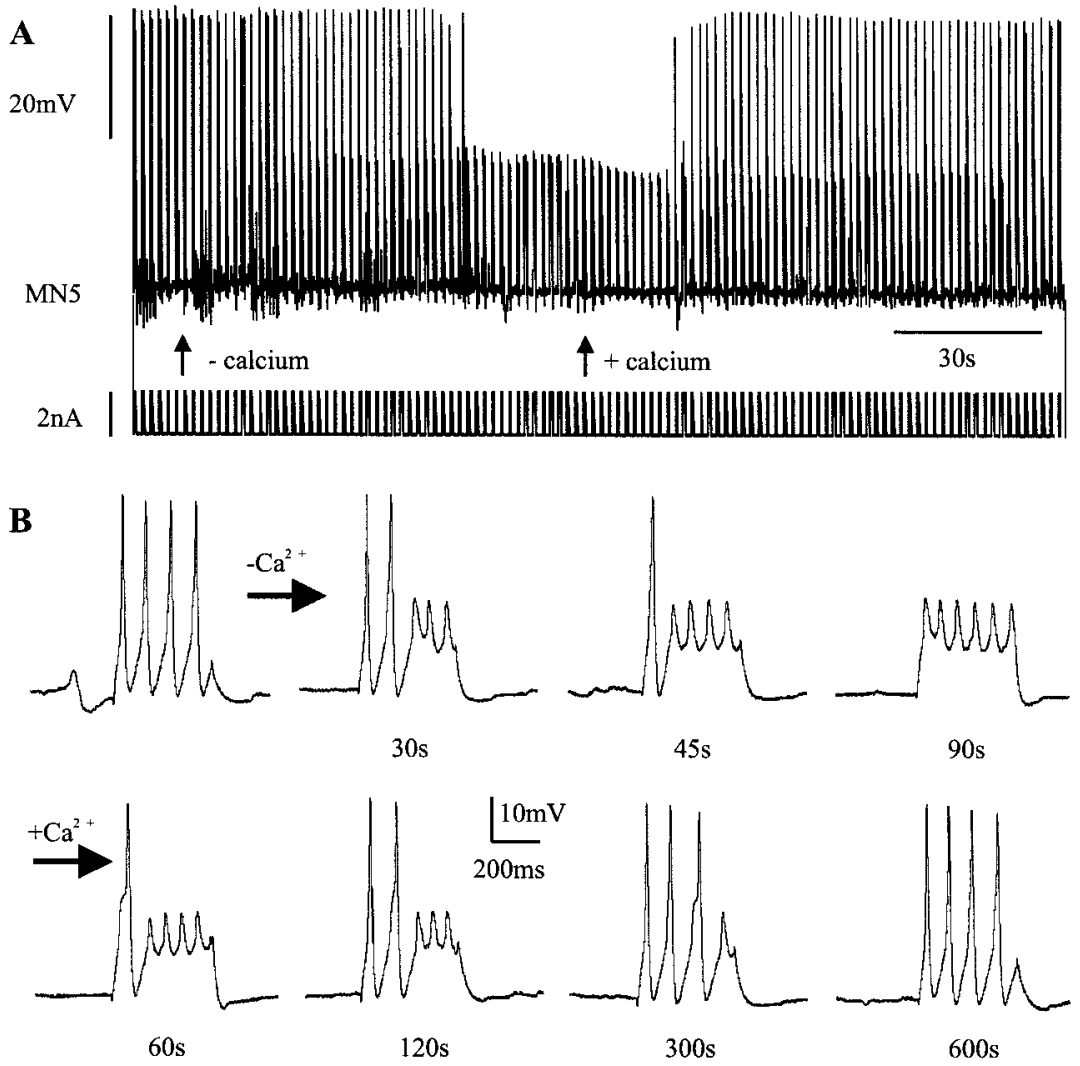

Figure 7. $\mathrm{MN} 5$ exhibits $\mathrm{Ca}^{2+}$ action potentials at pupal stages P7-P9. A, Representative continuous intracellular recording of MN5 at pupal stage P8. Somatic current injection (bottom trace) of $400 \mathrm{msec}$ duration at $0.6 \mathrm{~Hz}$ led to bursts of four large action potentials (top trace). Replacing external $\mathrm{Ca}^{2+}$ with $\mathrm{Mg}^{2+}$ (see left arrow) reduced the action potential amplitude significantly. This effect was reversed when $\mathrm{Mg}^{2}$ was replaced with $\mathrm{Ca}^{2+}$ (see right arrow). $B$, Single bursts taken at selected time points from the continuous recording shown in $A . C, \mathrm{Cd}^{2+}(0.5 \mathrm{mM})$ shown blocking the $\mathrm{Ca}^{2+}$-dependent component of the action potential in a recording of MN5 at pupal stage P7. D, A spontaneous action potential from a representative recording of MN5 at pupal stage P8 (left) and responses to electrical stimulation of a sensory nerve (right). Both subthreshold postsynaptic responses and $\mathrm{Ca}^{2+}$-dependent action potentials occurred in response to sensory stimulation.

C

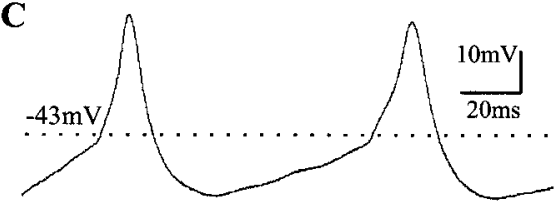

D

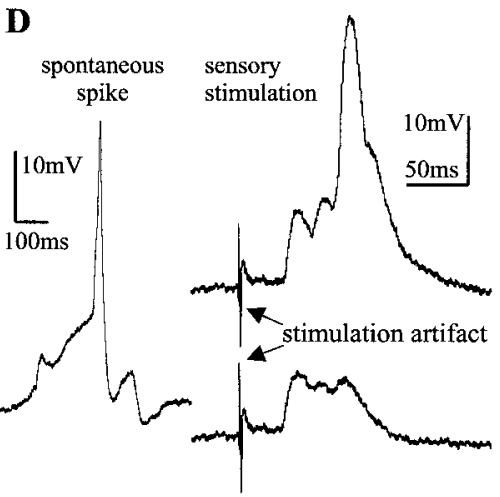

ing the transient $\mathrm{Ca}^{2+}$ spike during postembryonic dendritic remodeling of MN5.

\section{Changes in calcium and potassium currents during adult development}

For the analysis of $\mathrm{Ca}^{2+}$ currents, TTX $\left(10^{-8} \mathrm{M}\right)$ was added to the bath to block fast $\mathrm{Na}^{+}$currents, electrodes were filled with $1.5 \mathrm{M}$ $\mathrm{CsCl}$, and TEA was applied to the bath $(30 \mathrm{~mm})$. Nevertheless, outward currents were not blocked completely (Fig. 9A). After obtaining these records, therefore, $\mathrm{Ca}^{2+}$ currents were blocked with $\mathrm{Cd}^{2+}(0.5 \mathrm{~mm})$, and the residual outward current was subtracted (Fig. $9 A$ ) to allow calculation of the total $\mathrm{Ca}^{2+}$ current. Because there are some limitations to current analysis using singleelectrode voltage-clamp recordings in situ, the actual membrane voltage was monitored (Fig. 9A, top traces) to detect deviations from the command potential. The actual membrane voltages for commands between -10 and $10 \mathrm{mV}$ revealed slight depolarizing deflections during the maximum $\mathrm{Ca}^{2+}$ currents, but these were always $<5 \mathrm{mV}$ (Fig. 9A, top traces, arrow). Therefore, the voltageclamp control was adequate for comparing large differences in $\mathrm{Ca}^{2+}$ currents among developmental stages. The differences between the command and actual holding potential were consistent within a developmental stage, but the actual voltages reached for depolarizing commands above $-20 \mathrm{mV}$ differed among different developmental stages. Therefore, the instantaneous actual membrane voltage was used for the analysis of current/voltage relationships (see Fig. 9C).

The larval MN5 displayed a sustained $\mathrm{Ca}^{2+}$ current that was activated at approximately $-35 \mathrm{mV}$ and peaked at $\sim 5 \mathrm{mV}$ (Fig. $9 B, C)$. This corresponds to the description of $\mathrm{Ca}^{2+}$ currents in cultured leg motoneurons of Manduca sexta larvae, as measured from isolated somata with patch pipettes (Hayashi and Levine, 1992; Grünewald and Levine, 1998). No $\mathrm{Ca}^{2+}$ current was detected at pupal stages $\mathrm{P} 3$ and $\mathrm{P} 4$ (Fig. $9 B-D$ ). Two days later, at late pupal stage $\mathrm{P} 6, \mathrm{Ca}^{2+}$ currents were again expressed (Fig. 9B). The activation and the peak voltage were similar to the larval $\mathrm{Ca}^{2+}$ current, but the peak amplitude was twice as large (Fig. 9B). Furthermore, a transient component appeared in addition to the sustained $\mathrm{Ca}^{2+}$ current (Fig. 9B, arrows), although the components have not been separated pharmacologically or electrically. The amplitude of the transient $\mathrm{Ca}^{2+}$ current increased until pupal stage P8 (Fig. 9B-D). The occurrence of the maximum peak $\mathrm{Ca}^{2+}$ current correlated with the prominent $\mathrm{Ca}^{2+}$ spike at pupal stage 


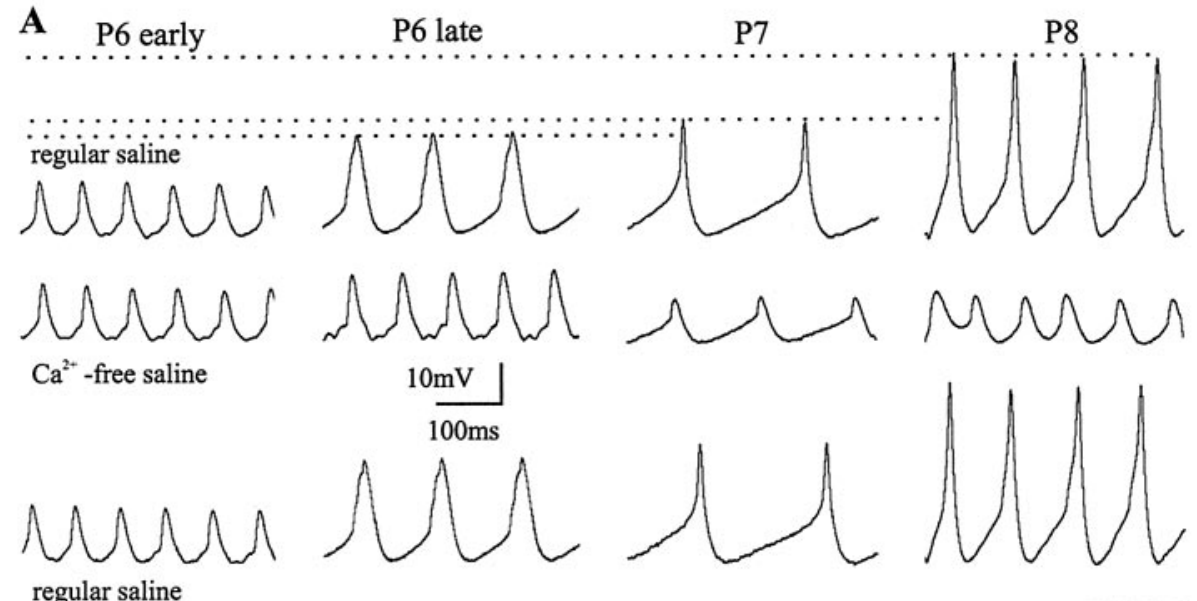

$\Delta$ spike amplitude

B

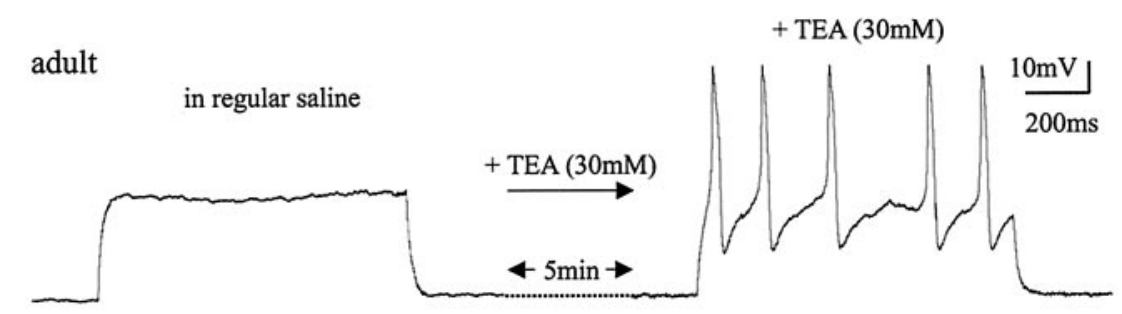

Figure 8. The amplitude of the $\mathrm{Ca}^{2+}$ spike increases between P6 and P8. $A, \mathrm{Ca}^{2+}$ was replaced with $\mathrm{Mg}^{2+}$ in recordings of MN5 at the pupal stages P6 early, P6 late, P7, and P8. Removal of external $\mathrm{Ca}^{2+}$ reduced the action potential amplitude at P6 late, P7, and P8. The action potential amplitude increased between P6 and P8 (top row; indicated by horizontal dotted lines). Similarly, the $\mathrm{Ca}^{2+}$ dependence of the action potential amplitude increased continuously between P6 and P8 (middle row) as indicated by the gray-shaded area. At all stages between P6 early and P8, the reduction in action potential amplitude in the absence of external $\mathrm{Ca}^{2+}$ was fully reversible (bottom row). B, Left, The representative response of the adult MN5 to current injections into the soma is shown. Right, Five minutes after bath application of TEA (30 $\mathrm{mM}$ ), the same MN5 responded with $\mathrm{Ca}^{2+}$. dependent action potentials to current injections.
P8. Neither the transient nor the sustained component of the $\mathrm{Ca}^{2+}$ current changed significantly during further development (Fig. $9 B-D)$, even though action potentials did not have a $\mathrm{Ca}^{2+}$ component from pupal stage P11 onward. Because a large $\mathrm{Ca}^{2+}$ dependent action potential could be unmasked by bath application of TEA at all developmental stages beyond P11, there may be an increase in voltage-activated $\mathrm{K}^{+}$currents between pupal stages P10 and P11.

To test this hypothesis, we compared the $\mathrm{K}^{+}$currents of MN5 at pupal stage P4 (no $\mathrm{Ca}^{2+}$ current present), pupal stage P8 $\left(\mathrm{Ca}^{2+}\right.$ currents fully developed and $\mathrm{Ca}^{2+}$ spike present), and pupal stage $\mathrm{P} 12\left(\mathrm{Ca}^{2+}\right.$ currents fully developed but no $\mathrm{Ca}^{2+}$ spike present). $\mathrm{K}^{+}$currents were measured with TTX $\left(10^{-8} \mathrm{M}\right)$ and $\mathrm{Cd}^{2+}(0.5$ $\mathrm{mM})$ in the bath solution. In contrast to the absence of voltageactivated $\mathrm{Ca}^{2+}$ currents at pupal stage P4, two different components of voltage-activated outward currents, a fast transient and a slower sustained component, were present at this developmental stage (Fig. 10A). Bath application of TEA (30 mM) blocked most of the sustained component, but the transient component was also reduced (Fig. 10A). Subtraction of the TEA-insensitive outward current from the total outward current revealed the TEA-sensitive sustained component (Fig. 10A). Although the transient and the sustained components were not isolated completely, they probably correspond to the "A-current" and the "delayed rectifier" $\mathrm{K}^{+}$ current revealed by patch-clamp analysis of isolated Manduca leg motoneurons (Hayashi and Levine, 1992; Grünewald and Levine, 1998).

In MN5 both components were present at all developmental stages between P4 and adult (data not shown). Earlier stages were not examined in this study. Because of contamination of the transient current by the rising phase of the sustained component and nonspecific pharmacological blocking of both components by TEA and 4-AP, the developmental fate of the individual components could not be investigated separately. Therefore, the net outward current at $350 \mathrm{msec}$ was measured (see Fig. 10 A, arrow). Currents were plotted against the actual voltage because of variable differences between the command potential and the actual membrane potential among different recordings. The $I-V$ relationships revealed no significant differences between pupal stages $\mathrm{P} 4$ and P8. In contrast, the net $\mathrm{K}^{+}$current was increased at pupal stage P12 because the slope of the fitted curve became significantly steeper (Fig. 10B). Because of this increase in $\mathrm{K}^{+}$current, the membrane voltage could not be held at values depolarized more than $-22 \mathrm{mV}$ using the single-electrode voltage-clamp technique, which allowed a maximum current of $\sim 20 \mathrm{nA}$ to pass. At pupal stage P12, the $\mathrm{K}^{+}$ currents reached a peak amplitude of $20 \mathrm{nA}$ at $-22 \mathrm{mV}$. In contrast, at pupal stages $\mathrm{P} 4$ and $\mathrm{P} 8$, maximum currents of $\sim 20 \mathrm{nA}$ were reached at approximately $-10 \mathrm{mV}$. It is not clear whether the increase in $\mathrm{K}^{+}$current measured after $350 \mathrm{msec}$ of each voltage step was caused by an increase in the sustained component or by a decrease in the inactivation of the transient component. However, total $\mathrm{K}^{+}$current was clearly larger at pupal stage P12 than at pupal stages P4 and P8 (Fig. 10B,C). This agrees with the finding that the $\mathrm{Ca}^{2+}$ spike disappeared at stages later than pupal stage P10 but could be unmasked by bath application of TEA (Fig. $8 B$ ).

\section{DISCUSSION}

\section{MN5 develops from a slow to a fast motoneuron}

The dendritic morphology and electrophysiological properties of MN5 change during postembryonic life. MN5 is more readily excitable in the larva than in the adult. Insect and crustacean motoneurons that innervate slowly contracting muscles are typically more excitable than those innervating rapidly contracting muscles. Slow or "tonic" motoneurons spike continuously during locomotion, whereas "phasic" motoneurons fire single spikes or brief bursts to induce rapid muscle contractions (Kennedy and Takeda, 1965a,b; Meyer and Walcott, 1979; Atwood and Wojtowicz, 1986; Burrows, 1996). In crustaceans, slow neuromuscular junctions can be converted into fast ones in an activity-dependent manner during postembryonic life (Lnenicka and Murphey, 1989). Here, we show that the excitability of an identified motoneuron can be modified according to changes in its behavioral function during postembryonic development. Its larval target muscle is involved in slow crawling movements (Kammer and Rheuben, 1976; Rheuben and Kammer, 1980), in which it must maintain tonic tension. In contrast, flight motoneurons ordinarily fire once to twice per wing- 

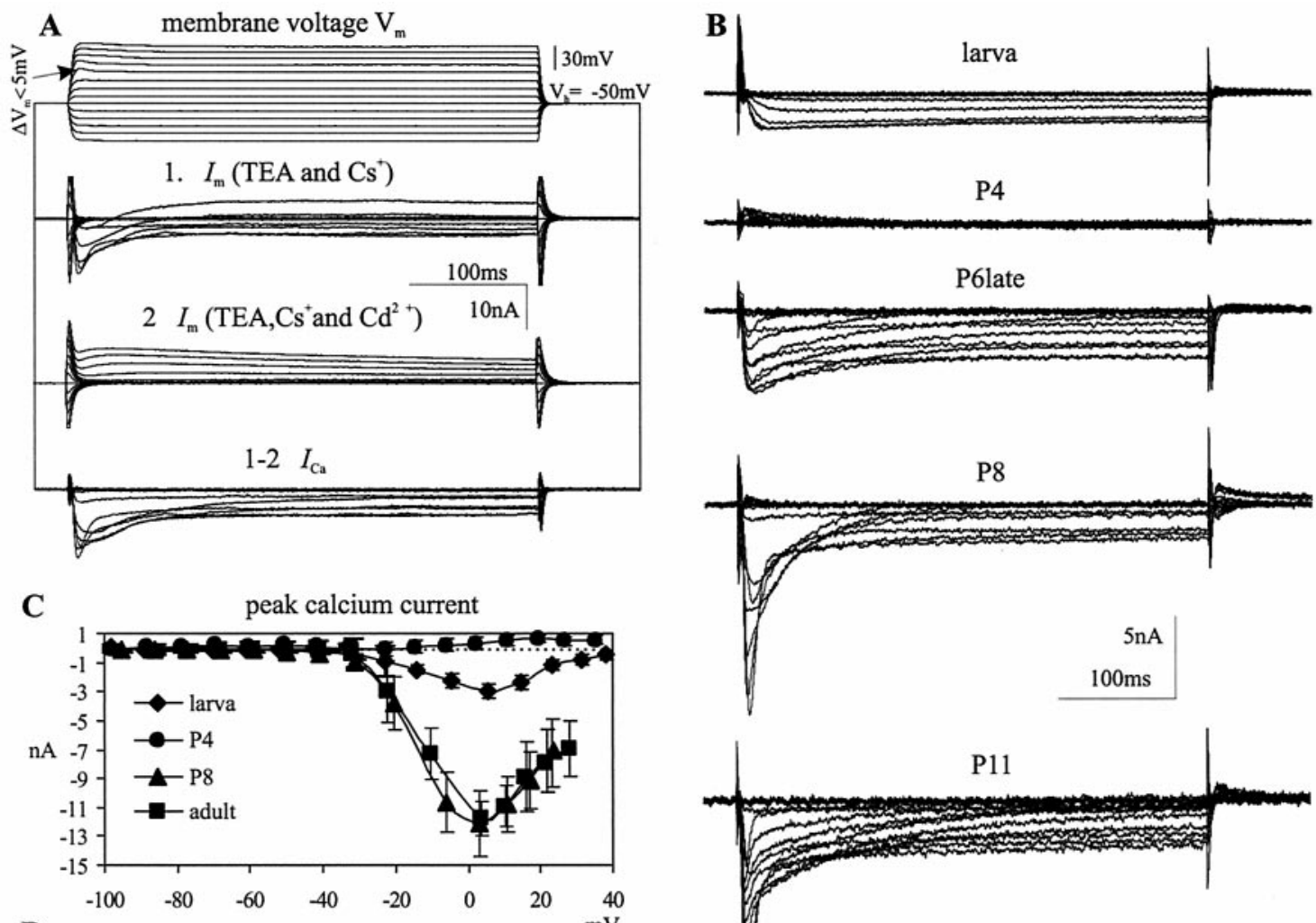

D

average peak and sustained calcium currents

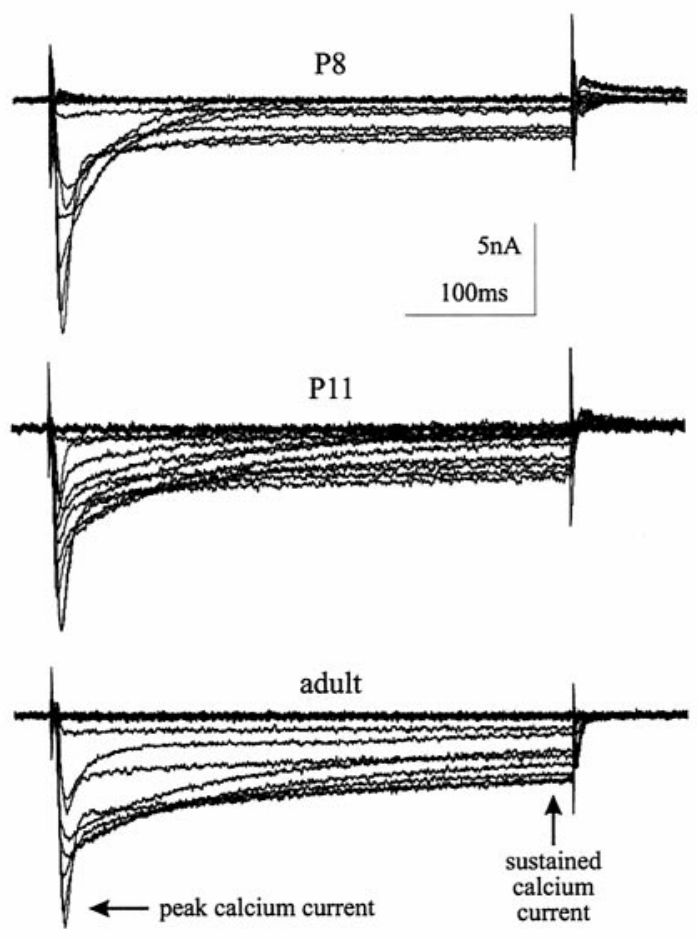

Figure 9. Developmental modifications of calcium currents in MN5. A, Representative membrane current $\left(I_{\mathrm{m}}\right)$ recordings in dSEVC mode of MN5 at pupal stage P7 to demonstrate the method used for isolating $\mathrm{Ca}^{2+}$ currents (see Results). The actual membrane potential was monitored in all experiments. Slight voltage fluctuations were sometimes observed at the membrane potentials at which the maximum $\mathrm{Ca}^{2+}$ currents occurred, but these were always $<5 \mathrm{mV}$ (see arrow). $B$, Representative traces of inward currents for different developmental stages after subtraction (see $A$ ). The time points where peak and sustained $\mathrm{Ca}^{2+}$ currents were measured are indicated with arrows. $C, I-V$ relationships for the peak $\mathrm{Ca}^{2+}$ current created from four recordings each in the larval stage, pupal stages P4 and P8, and the adult. $D$, Average peak and sustained $\mathrm{Ca}^{2+}$ currents for different developmental stages. The number of recordings for each group is presented below each set of bars. Error bars represent SDs.

beat cycle to mediate fast twitch contractions but no muscle tonus (Zarnack and Möhl, 1977; Burrows, 1996).

The lower excitability of the adult MN5 is caused by a more hyperpolarized resting potential, a more depolarized firing threshold, and a fivefold lower input resistance. Major decreases in input resistance and tonic firing occur during the onset of dendritic growth, but input resistance remains relatively constant throughout all later stages despite significant cell growth. Therefore, changes in excitability are not simply reflective of changes in cell size. The excitability of MN5 is adult-like at pupal stage P11. This correlates with an increase in the net $\mathrm{K}^{+}$current between pupal stages P8 and P12. Similarly, in Xenopus embryonic development, modifications in $\mathrm{K}^{+}$currents in spinal neurons are correlated with the maturation of motor patterns (Sun and Dale, 1998). For MN5, the low excitability during late pupal stages is important because contractions of the pupal DLM muscle, which is striated and functionally innervated by pupal stage P8 (Duch et al., 2000), would tear the soft newly formed adult cuticle.

$\mathrm{Ca}^{2+}$ conductances that are independent of the spike-initiating zone play a major role in the generation of plateau potentials (Hartline and Russel, 1984; Schwindt and Crill, 1984; Hancox and
Pitman, 1991, 1993; Kiehn, 1991). Although the adult MN5 displayed no plateau potentials in the isolated ganglion preparation, prolonged $\mathrm{Ca}^{2+}$ action potentials could be evoked after applying TEA. In many systems, plateau potentials can be induced by neuromodulators or any intervention that sufficiently reduces opposing outward currents (Ramirez and Pearson, 1991; Hultborn and Kiehn, 1992; Kiehn and Harris-Warrick, 1992; Bal et al., 1994). Flight is strongly influenced by neuromodulators, such as octopamine, which evokes plateau potentials in locust flight interneurons (Orchard et al., 1993). Moths display a prolonged warm-up phase during which neuromodulators may prepare the CNS for flight behavior (Claassen and Kammer, 1986). Thus, the $\mathrm{Ca}^{2+}$ current detected in the adult MN5 might be important in shaping its motor output, particularly if neuromodulators reduce $\mathrm{K}^{+}$currents during flight.

In contrast to the adult, $\mathrm{Ca}^{2+}$ spikes are readily produced during pupal stages $\mathrm{P} 7$ to $\mathrm{P} 9$. At later stages the $\mathrm{Ca}^{2+}$ spike is masked by the increased $\mathrm{K}^{+}$currents. The large amplitude of the $\mathrm{Ca}^{2+}$ spike in somatic recordings suggests that these spikes are generated in the cell body, although it is unclear where they are initiated. In contrast, the small amplitude of the $\mathrm{Na}^{+}$spike as recorded from 
$\mathbf{A}$

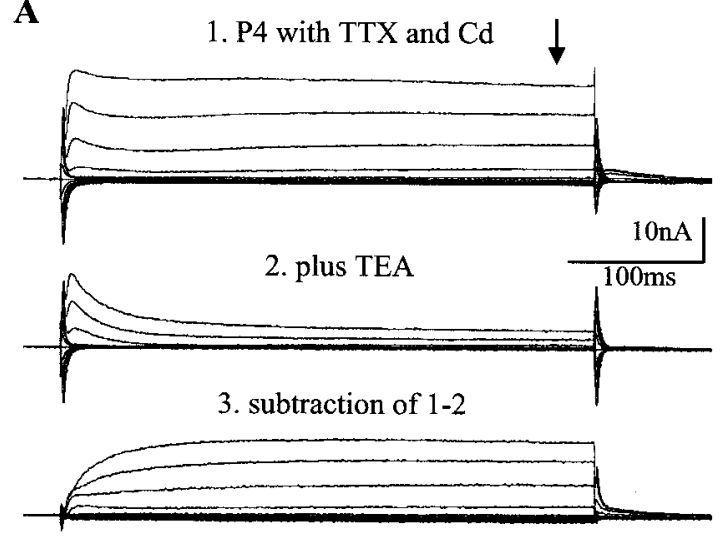

B

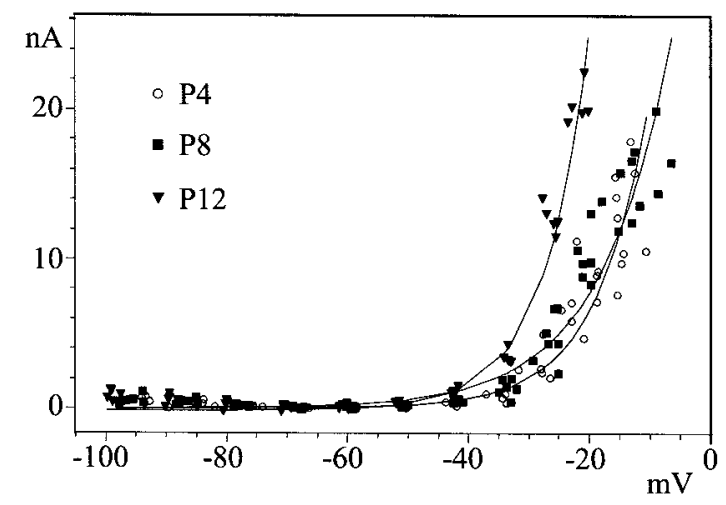

C

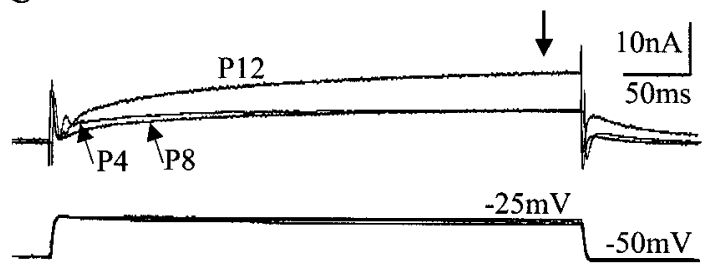

Figure 10. Developmental modifications of potassium currents in MN5. $A$, Panel 1, Total potassium current was recorded in dSEVC mode from MN5 at pupal stage P4 with TTX $\left(10^{-8} \mathrm{M}\right)$ and cadmium $(0.5 \mathrm{M})$ in the bath. Panel 2, Bath application of TEA $(30 \mathrm{~mm})$ affected the sustained component of the outward current significantly, although the transient component was also reduced. Panel 3, Subtraction of the residual transient component from the total outward current revealed the sustained component. $B, I-V$ relationships for the total potassium current (see traces in $A$ ) at pupal stages $\mathrm{P} 4, \mathrm{P} 8$, and $\mathrm{P} 12$ are shown. Total current was measured at $350 \mathrm{msec}$ of each voltage step (see arrow in $A$ ) and plotted against the actual instantaneous membrane potential (see Results). Five recordings were plotted for each stage, and curves were fitted using the simplex method. The $I-V$ relationships for pupal stages P4 and P8 showed no significant difference, but the fitted curve for pupal stage P12 was significantly steeper. $C$, Typical current responses of MN5 at the stages P4, P8, and P12 are shown after bath application of TTX and cadmium to voltage steps from a holding potential of $-50 \mathrm{mV}$ to an actual membrane potential of $-25 \mathrm{mV}$. The bottom traces show the voltages recorded at the three different stages, and the top traces show the current responses.

the soma at most stages, and evident at stages P7 to P9 after removal of external $\mathrm{Ca}^{2+}$, indicates that these spikes are not actively generated in the cell body, similar to the usual case for insect motoneurons (Gwilliam and Burrows, 1980).

\section{MN5 undergoes sequential changes in ionic currents during postembryonic life}

Embryonic and postnatal maturation of central neurons is accompanied by a sequential expression of different voltage-activated ionic currents (for review, see Spitzer, 1991). We report sequential modifications in $\mathrm{Ca}^{2+}$ and $\mathrm{K}^{+}$currents during the postembryonic acquisition of a new behavior.

The validity of the in situ single-electrode voltage-clamp measurements is supported by findings obtained from a population of cultured motoneurons recorded in the whole-cell patch configuration. Leg motoneuron somata that were isolated acutely from early pupal Manduca had smaller $\mathrm{Ca}^{2+}$ current densities than did those isolated from larvae or adults but retained some $\mathrm{K}^{+}$currents (Hayashi and Levine, 1992). Although these measurements from isolated somata avoided space-clamp problems, the extent to which they represented normal physiology and their functional consequences were unclear. Thus, the in situ measurements reported here were indispensable for defining the normal sequence of ionic current expression during development. The absence of $\mathrm{Ca}^{2+}$ currents in MN5 at early pupal stages in vivo was not an artifact attributable to space-clamp problems, because MN5 was much smaller at these stages than at other stages in which $\mathrm{Ca}^{2+}$ currents were detected. By contrast, the net $\mathrm{K}^{+}$current did not change between $\mathrm{P} 4$ and $\mathrm{P} 8$ but increased after stage P12. These findings allow a correlation of physiological changes that are evident during normal development with the time course of dendritic remodeling.

\section{Putative signals for changes in ionic currents during postembryonic development}

The steroid hormone 20-hydroxyecdysone (20E) may regulate the modification of $\mathrm{Ca}^{2+}$ currents. Manduca leg motoneurons cultured during early pupal stages show a 20E-dependent increase in $\mathrm{Ca}^{2+}$ current (Grünewald and Levine, 1998). Systemic ecdysteroid levels rise continuously between stages P4 and P8 (Bollenbacher et al., 1981), while $\mathrm{Ca}^{2+}$ currents in MN5 increase. Ecdysteroids regulate the excitability of neurosecretory neurons in Manduca (Hewes and Truman, 1994), perhaps by altering ionic currents, and steroid hormones are potent modulators of ionic currents in the vertebrate CNS (Kerr et al., 1992; Rendt et al., 1992; Dunlap et al., 1997). Alternatively, activity-dependent mechanisms could be involved, because electrical activity influences the postnatal shaping of neuronal connections (Shatz, 1990; Fields and Nelson, 1992; Gu and Spitzer, 1995) and the expression of ion currents (Garcia et al., 1994; Lnenicka et al., 1998). Finally, interactions with the degenerating larval target muscle during late larval and early pupal stages (Duch et al., 2000) might play a role. The trigger for the increase in net $\mathrm{K}^{+}$current between pupal stages $\mathrm{P} 8$ and $\mathrm{P} 12$ also remains to be investigated. Systemic ecdysteroid levels decline during these stages (Bollenbacher et al., 1981), but 20E had no effect on the $\mathrm{K}^{+}$ currents of cultured pupal leg motoneurons (Grünewald and Levine, 1998). Alternatively, the large $\mathrm{Ca}^{2+}$ current at stage $\mathrm{P} 8 \mathrm{might}$ play a role, similar to the role of a $\mathrm{Ca}^{2+}$ influx-dependent increase in $\mathrm{K}^{+}$channel expression during the postnatal maturation of Purkinje cells (Muller et al., 1998).

\section{Possible role of transient calcium signals in dendritic differentiation}

Similar to other central neurons in Manduca (Levine and Truman, 1985; Weeks and Ernst-Utzschneider, 1989; Kent and Levine, 1993), MN5 undergoes dramatic dendritic remodeling during metamorphosis. Some aspects of the dendritic plasticity are controlled directly by 20E (for review, see Weeks and Levine, 1990, 1995), but interactions with the periphery are also involved (Kent and Levine, 1993). This is the first study in which dendritic remodeling can be correlated temporally with changes in active and passive membrane properties during normal postembryonic development. This correlation is consistent with a role for $\mathrm{Ca}^{2+}$ influx in dendritic remodeling. Prominent growth cone-like structures form at the tips of the growing adult dendrites between pupal stages P2 and P6. This corresponds in time with a low level of $\mathrm{Ca}^{2+}$ currents. In culture systems, low levels of $\mathrm{Ca}^{2+}$ influx promote growth cone extension and branching, but high levels of influx and prolonged internal elevation inhibit these processes (for review, see Kater et al., 1988; Kater and Mills, 1991). The cessation of the 
formation of high-order branches of MN5 is correlated with the transient occurrence of $\mathrm{Ca}^{2+}$ spikes during pupal stages $\mathrm{P} 7$ to $\mathrm{P} 9$, because of the differential timing of $\mathrm{Ca}^{2+}$ versus $\mathrm{K}^{+}$current modifications. Because these spikes occurred spontaneously and could be evoked by sensory stimulation in the isolated ganglion preparation, it is likely that they also occur during normal development. During embryonic spinal cord development, the frequency of growth cone $\mathrm{Ca}^{2+}$ transients is inversely proportional to the rate of axon outgrowth, with large elevations in internal $\mathrm{Ca}^{2+}$ at pausing sites (Gomez and Spitzer, 1999), causing an increase in the activity of calcineurin (Lautermilch and Spitzer, 2000). Furthermore, the $\mathrm{Ca}^{2+}$-sensitive enzyme calmodulin kinase II is required to limit the elaboration of neuronal arbors in the developing Xenopus optical tectum (Zou and Cline, 1999). The effects of postembryonic $\mathrm{Ca}^{2+}$ current modifications on cytosolic $\mathrm{Ca}^{2+}$ levels of MN5 remain to be investigated. However, the ability to correlate structural and functional events in their normal context in this system provides distinct advantages for examining whether $\mathrm{Ca}^{2+}$ signals mediate the initiation and cessation of dendritic growth during postembryonic life.

\section{REFERENCES}

Atwood HL, Wojtowicz JM (1986) Short-term and long-term plasticity and physiological differentiation of crustacean motor synapses. Int Rev Neurobiol 28:275-362.

Baines RA, Bate M (1998) Electrophysiological development of central neurons in the Drosophila embryo. J Neurosci 18:4673-4683.

Bal T, Nagy F, Moulin M (1994) Muscarinic modulation of a patterngenerating network: control of neuronal properties. J Neurosci 14:3019-3035.

Bell RA, Joachim FA (1976) Techniques for rearing laboratory colonies of tobacco hornworms and pink ballworms. Ann Entomol Soc Am 69:365-373.

Bollenbacher WE, Smith SL, Goodman W, Gilbert LI (1981) Ecdysteroid titer during the larval-pupal-adult development of the tobacco hornworm, Manduca sexta. Gen Comp Endocrinol 44:302-306.

Burrows M (1996) Components of the nervous system: motoneurons. In: The neurobiology of an insect brain. New York: Oxford UP.

Casaday GB, Camhi JM (1976) Metamorphosis of flight motoneurons in the moth, Manduca sexta. J Comp Physiol [A]112:143-158.

Casanovas B, Meyrand P (1995) Functional differentiation of adult neural circuits from a single embryonic network. J Neurosci 15:5703-5718.

Claassen DE, Kammer AE (1986) Effects of octopamine, dopamine, and serotonin on production of flight motor output by thoracic ganglia of Manduca sexta. J Neurobiol 17:1-14.

Cohan CS, Connor JA, Kater SB (1987) Electrically and chemically mediated increases in intracellular calcium in neuronal growth cones. J Neurosci 7:3588-3599.

Consoulas C, Kent KS, Levine RB (1996) Remodeling of the peripheral processes and presynaptic terminals of leg motoneurons during metamorphosis of the hawkmoth, Manduca sexta. J Comp Neurol 372:415-434.

Duch C, Bayline RJ, Levine RB (2000) Postembryonic development of the dorsal longitudinal flight muscle and its innervation in Manduca sexta. J Comp Neurol, in press.

Dunlap KD, McAnelly ML, Zakon HH (1997) Estrogen modifies an electrocommunication signal by altering the electrocyte sodium current in an electric fish, Sternopygus. J Neurosci 17:2869-2875.

Fields RD, Nelson PG (1992) Activity-dependent development of the vertebrate nervous system. Int Rev Neurobiol 25:281-293.

Fields RD, Neale EA, Nelson PG (1990) Effects of patterned electrical activity on neurite outgrowth from mouse sensory neurons. J Neurosci 10:2950-2964.

Gao BX, Ziskind-Conhaim L (1998) Development of ionic currents underlying changes in action potential waveforms in rat spinal motoneurons. J Neurophysiol 80:3047-3061.

Garcia DE, Cavalie A, Lux HD (1994) Enhancement of voltage-gated calcium currents induced by daily stimulation of hippocampal neurons with glutamate. J Neurosci 14:545-553.

Gomez MG, Spitzer NC (1999) In vivo regulation of axon extension and pathfinding by growth-cone calcium transients. Nature 397:350-355.

Grünewald B, Levine RB (1998) Ecdysteroid control of ionic current development in Manduca sexta motoneurons. J Neurobiol 37:211-223.

Gu X, Spitzer NC (1995) Distinct aspects of neuronal differentiation encoded by frequency of spontaneous calcium transients. Nature 375:784-787.

Gwilliam GF, Burrows M (1980) Electrical characteristics of an identified insect motoneuron. J Exp Biol 86:49-60.

Hancox JC, Pitman RC (1991) Plateau potentials drive axonal impulse bursts in insect motoneurons. Proc R Soc Lond B Biol Sci 244:33-38.
Hancox JC, Pitman RC (1993) Plateau potentials in insect motoneurons can be driven by synaptic input. J Exp Biol 176:307-310.

Hartline DK, Russel DF (1984) Endogenous burst capability in a neuron of the gastric mill pattern generator of the spiny lobster Panulirus interruptus. J Neurobiol 15:345-364.

Hayashi JH, Levine RB (1992) Calcium and potassium currents in leg motoneurons during postembryonic development in the hawkmoth Manduca sexta. J Exp Biol 171:15-42.

Haydon PG, Zoran MJ (1994) Retrograde regulation of presynaptic development during synaptogenesis. J Neurobiol 25:694-706.

Hewes RS, Truman JW (1994) Steroid regulation of excitability in identified insect neurosecretory cells. J Neurosci 14:1812-1819.

Hultborn H, Kiehn O (1992) Neuromodulation of vertebrate motoneuron membrane properties. Curr Opin Neurobiol 2:770-775.

Kammer AE, Rheuben MB (1976) Adult motor patterns produced by the moth pupae during development. J Exp Biol 65:65-84.

Kater SB, Mills LR (1991) Regulation of growth cone behavior by calcium. J Neurosci 11:891-899.

Kater SB, Mattson MP, Cohan C, Connor J (1988) Calcium regulation of neuronal growth cone. Trends Neurosci 11:315-321.

Kennedy D, Takeda K (1965a) Reflex control of abdominal flexor muscles in the crayfish. I. The twitch system. J Exp Biol 43:211-227.

Kennedy D, Takeda K (1965b) Reflex control of abdominal flexor muscles in crayfish. II. The tonic system. J Exp Biol 43:229-246.

Kent KS, Levine RB (1993) Dendritic reorganization of an identified neuron during metamorphosis of the moth, Manduca sexta-the influence of interactions with the periphery. J Neurobiol 24:1-22.

Kerr DS, Campbell LW, Thibault O, Landfield PW (1992) Hippocampal glucocorticoid receptor activation enhances voltage-dependent calcium conductances: relevance for brain aging. Proc Natl Acad Sci USA $89: 8527-8531$

Kiehn O (1991) Plateau potentials and active integration in the "final common pathway" for motor behavior. Trends Neurosci 14:68-73.

Kiehn O, Harris-Warrick RM (1992) Seretonergic stretch receptors induce plateau properties in a crustacean motoneuron by a dualconductance mechanism. J Neurophysiol 68:485-495.

Lautermilch NJ, Spitzer NC (2000) Regulation of calcineurin by growth cone calcium waves controls neurite extension. J Neurosci 20:315-325.

Levine RB, Truman JW (1982) Metamorphosis of the insect nervous system: changes in the morphology and synaptic interactions of identified cells. Nature 299:250-252.

Levine RB, Truman JW (1985) Dendritic reorganization of abdominal motoneurons during metamorphosis of the moth Manduca sexta. J Neurosci 5:2424-2431.

Lnenicka GA, Murphey RK (1989) The refinement of invertebrate synapses during development. J Neurobiol 20:339-355.

Lnenicka GA, Arcaro KF, Calabro JM (1998) Activity-dependent development of calcium regulation in growing motor axons. J Neurosci 18:4966-4972.

Martin-Caraballo M, Greer JJ (1999) Electrophysiological properties of rat phrenic motoneurons during perinatal development. J Neurophysiol 81:1365-1378

Mattson MP, Dou P, Kater SB (1988) Outgrowth-regulating actions of glutamate in isolated hippocampal pyramidal neurons. J Neurosci 8:2087-2100.

McCobb DP, Best PM, Beam KG (1989) Development alters the expression of calcium currents in chick limb motoneurons. Neuron 2:1633-1643.

McCobb DP, Best PM, Beam KG (1990) The differentiation of excitability on embryonic chick limb motoneurons. J Neurosci 10:2974-2984.

Meyer D, Walcott B (1979) Differences in the responsiveness of identified motoneurons in the cockroach: role for the motor program for stepping. Brain Res 178:600-605

Muller YL, Reitstetter R, Yool AJ (1998) Regulation of $\mathrm{Ca}^{2+}$-dependent $\mathrm{K}^{+}$channel expression in rat cerebellum during postnatal development. J Neurosci 18:16-25.

Nijhout HF, Williams CM (1974) Control of molting and metamorphosis in the tobacco hornworm, Manduca sexta (L): growth of the last instar larva and the decision to pupate. J Exp Biol 61:481-491.

Orchard I, Ramirez JM, Lange AB (1993) A multifunctional role for octopamine in locust flight. Annu Rev Entomol 38:227-249.

Ramirez JM, Pearson KG (1991) Octopamine induces bursting and plateau potentials in insect neurons. Brain Res 549:332-337.

Rendt JM, Toro L, Stefani E, Eruklar SD (1992) Progesterone increases calcium currents in myometrial cells from immature and nonpregnant adult rats. Am J Physiol 262:C293-C301.

Reynolds SA, French KA, Baader A, Kristan Jr WB (1998) Development of spontaneous behaviors in the medical leech. J Comp Neurol 14:168-180.

Rheuben MB, Kammer AE (1980) Comparison of slow larval and fast adult muscle innervated by the same motoneuron. J Exp Biol 84:103-112.

Ribiera AB, Spitzer NC (1992) Developmental regulation of potassium channels and the impact on neuronal differentiation. Ion Channels $3: 1-38$.

Schwindt PC, Crill WE (1984) Membrane properties of cat spinal motoneurons. In: Handbook of the spinal cord (Davidoff RA, ed), pp 199-242. New York: Dekker. 
Shatz CJ (1990) Impulse activity and the patterning of connections during CNS development. Neuron 5:745-756.

Spitzer NC (1991) A developmental handshake: neuronal control of ionic currents and their control of neuronal differentiation. J Neurobiol 22:659-673

Sun QQ, Dale N (1998) Developmental changes in expression of ionic currents accompany maturation of locomotor pattern in frog tadpoles. J Physiol (Lond) 507:257-264.

Tolbert LP, Matsumotu SG, Hildebrand JG (1983) Development of synapses in the antennal lobes of the moth Manduca sexta during metamorphosis. J Neurosci 3:1158-1175.

Truman JW, Reiss SE (1988) Hormonal regulation of the shape of identified motoneurons in Manduca sexta. J Neurosci 8:765-775.

Weeks JC, Ernst-Utzschneider K (1989) Respecification of larval proleg motoneurons during metamorphosis of the tobacco hornworm, Manduca sexta. Segmental dependence and hormonal regulation. J Neurobiol 20:569-592.

Weeks JC, Levine RB (1990) Postembryonic neuronal plasticity and its hormonal control during insect metamorphosis. Annu Rev Neurosci 13:183-194.

Weeks JC, Levine RB (1995) Steroid hormone effects on neurons subserving behavior. Curr Opin Neurobiol 5:809-815.

Zarnack W, Möhl B (1977) Activity of the downstroke flight muscles of Locusta migratoria (L.) during steering behavior in flight. J Comp Physiol [A] 118A:215-233.

Zou DJ, Cline HT (1999) Postsynaptic calcium/calmodulin-dependent kinase II is required to limit elaboration of presynaptic and postsynaptic neuronal arbors. J Neurosci 19:8909-8918. 